\title{
Review Article Noncoding RNAs in Vascular Aging
}

\author{
Qidong Cao, ${ }^{1}$ Jiuping Wu, ${ }^{2}$ Xiaoli Wang, ${ }^{3}$ and Chunli Song $\mathbb{D}^{1}$ \\ ${ }^{1}$ Department of Cardiology, The Second Hospital Affiliated to Jilin University, Chang Chun, Jilin, China \\ ${ }^{2}$ Department of Spinal Surgery, The Second Hospital Affiliated to Jilin University, Chang Chun, Jilin, China \\ ${ }^{3}$ Department of Pneumology, Qingdao Women and Children's Hospital, Qingdao, Shandong, China
}

Correspondence should be addressed to Chunli Song; 2632494613@qq.com

Received 23 July 2019; Revised 20 November 2019; Accepted 17 December 2019; Published 6 January 2020

Academic Editor: Roberto Carnevale

Copyright (c) 2020 Qidong Cao et al. This is an open access article distributed under the Creative Commons Attribution License, which permits unrestricted use, distribution, and reproduction in any medium, provided the original work is properly cited.

\begin{abstract}
Increases in age are accompanied by vascular aging, which can lead to a variety of chronic diseases, including atherosclerosis and hypertension. Noncoding RNAs (ncRNAs) have become a research hotspot in different fields of life sciences in recent years. For example, these molecules have been found to have regulatory roles in many physiological and pathological processes. Many studies have shown that microRNAs (miRNAs) and long ncRNAs (lncRNAs) also play a regulatory role in vascular aging. Endothelial cells (ECs) and vascular smooth muscle cells (VSMCs) are important components of blood vessels, and the senescence of both cell types promotes the occurrence of vascular aging. This review provides a contemporary update on the molecular mechanisms underlying the senescence of ECs and VSMCs and the regulatory role of miRNAs and lncRNAs in this process.
\end{abstract}

\section{Introduction}

Cardiovascular disease is a common cause of death among the elderly. The mortality rate due to heart disease and stroke is known to increase exponentially with increased age, accounting for more than $40 \%$ of the total deaths of 65 to 74 -year-old patients and nearly $60 \%$ of the total deaths of patients over 85 years old. Vascular aging is an independent risk factor for age-related diseases, especially cardiovascular diseases such as atherosclerosis, hypertension, and stroke, which are characterized by increased vascular stiffness and pulse wave velocity (PWV), enlarged lumens, and decreased vascular elasticity based on functional and morphological assessments $[1,2]$. It is clear that vascular aging increases the risk of developing cardiovascular diseases.

It is accepted that $1-2 \%$ of the human genome is proteincoding, while the remaining $98 \%$ is mostly transcribed into RNA with no or minimal protein-coding potential, known as noncoding RNA (ncRNA). Studies suggest that these molecules act as key regulators in many biological processes including gene expression, cell cycle control, apoptosis, cell differentiation, chromatin remodeling, and epigenetic modifications [3, 4]. ncRNAs include "housekeeping" RNAs such as ribosomal RNA (rRNA) and transfer RNA (tRNA), as well as regulatory RNAs. Regulatory RNAs are categorized into small ncRNAs, which are shorter than $200 \mathrm{nt}$, and long ncRNAs (lncRNAs; > $200 \mathrm{nt}$ ) according to their transcript length. Small regulatory ncRNAs include microRNAs (miRNAs), PIWI-interacting RNAs (piRNAs), and endogenous small interfering RNAs (endo-siRNAs). Among them, a large number of studies have focused on the regulatory role of miRNAs and lncRNAs in the process of vascular aging.

Vascular smooth muscle cells (VSMCs) and endothelial cells (ECs) are the main components of blood vessels, and senescence in these cell types is thought to contribute to vascular aging and age-related diseases. Cell senescence is affected by many pathological and clinical factors, such as inflammation and diabetes. Inflammation plays an important role in cell senescence; some cytokines (such as nuclear factor- $\kappa \mathrm{B}(\mathrm{NF}-\kappa \mathrm{B})$, CCAAT-enhancer-binding protein $\beta$ $(\mathrm{C} / \mathrm{EBP} \beta)$, and signal transducer and activator of transcription 3 (STAT3)) promote cell senescence [5]. In addition, it was found that hyperglycemia promotes endothelial cell senescence, and some miRNAs have been proven to play a role in diabetes mellitus and its vascular complications $[6,7]$. In addition, hyperglycemia also promotes myocardial 
aging by activating miR-34a [8]. The mechanism by which these pathophysiological factors lead to vascular aging is an interesting topic of research.

Many studies have found that miRNAs and lncRNAs regulate the occurrence and development of vascular aging, leading to vascular aging-related dysfunction and diseases. Thus, it is necessary to develop clinical strategies for delaying vascular aging by targeting ncRNAs. Here, we review current research on the role of miRNAs and lncRNAs in $\mathrm{EC}$ and VSMC senescence. Furthermore, the major miRNAs and lncRNAs that influence senescence of ECs and VSMCs are introduced, and their roles in controlling vascular aging are discussed.

\section{Senescence of ECs and VSMCs}

Cell senescence can be defined as cell cycle arrest accompanied by the depletion of replication potential [9]. Senescent cells are characterized based on morphology (vacuolation, flattening cells) and the expression of specific markers such as senescence-related $\beta$-galactosidase (SA $\beta \mathrm{G})$ [10]. Cell senescence has been categorized into two processes based on its causes: replicative senescence (RS) and stressinduced premature senescence (SIPS). Normal somatic cells cannot maintain their replicative capacity indefinitely, and thus, they eventually enter a state of growth arrest [11]. When cells are cultured in vitro, the telomeres shorten gradually and eventually reach the Hayflick limit, triggering the DNA damage response (DDR) and RS [12]. In turn, exposure to angiotensin II, oxidative stress, and mitochondrial and DNA damage can induce cellular senescence, which is referred to as SIPS [13].

Telomeres are repetitive TTAGGG DNA sequences located at the end of chromosomes that protect DNA from damage. Telomerase, a telomeric repeat synthase, is used to maintain the telomere length. Mechanically, critical telomere shortening is thought to trigger the onset of cellular senescence, and telomerase activity regulates cell proliferation in normal somatic cells by lengthening the telomere, or via telomere length-independent mechanisms [14]. Human ECs and VSMCs exhibit telomerase activity activated by mitogenic stimuli via a protein kinase C-dependent pathway [15]. However, the activity of telomerase declines with aging because of a decrease in the expression of telomerase reverse transcriptase (TERT), leading to telomere shortening and cellular senescence $[16,17]$. One study found that the addition of $\mathrm{NO}$ to ECs rescued the replicative reduction of telomerase activity [18].

RS and SIPS are mediated by two distinct and partially intersecting pathways [19]. RS involves the p53 factor and its immediate transcriptional target $\mathrm{p} 21$, whereas SIPS involves p16 and retinoblastoma protein (pRB). Both p16 and p21 induce cell cycle arrest through the inhibition of cyclin-dependent kinases (CDKs), resulting in pRB activation [19]. The function of EC gradually declines with age, resulting in the progression to a systemic inflammatory state known as "inflammatory aging" [20]. In this state, cells exhibit a characteristic senescence-related secretory phenotype, characterized by high levels of matrix metalloprotein- ases (MMPs) and inflammatory cytokines [21]. Endothelial dysfunction induced by EC senescence includes the impairment of endothelium-dependent vasodilation, angiogenesis, and the antithrombotic properties of the endothelium [22]. Both NO production and endothelial NO synthase activity are reduced in senescent human vascular ECs, which show increased vasoconstrictive activity [23, 24]. In addition, NO inhibits platelet aggregation and blocks neutrophil/monocyte adhesion to ECs $[25,26]$. However, NO depletion can lead to the dysfunction of vascular homeostasis and the development of hypertension, thrombosis, and atherosclerosis $[27,28]$.

VSMCs also play a key role in vascular aging and contribute to the occurrence and development of atherosclerosis [29]. In addition, VSMC senescence increases the vulnerability of atherosclerotic plaques [30]. VSMCs change from a contractile state to a synthetic one during vascular impairment, hypertension, or atherosclerosis [31]. miRNAs have been identified as key regulators of VSMC biology. For example, it was found that reduced miR-23b activity induces phenotypic switching in VSMCs after vascular injury [32]. Similarly, phenotypic switching of VSMCs is also common during vascular aging, making the cardiovascular system prone to disease even in the absence of traditional risk factors [33]. Senescence phenotypes also include a loss of VSMCs in media and markers of premature senescence including increased $\mathrm{Sa} \beta \mathrm{G}$ expression, reduced telomere lengths, and a decrease in the number of Ki67-positive cells [34]. The loss of VSMCs can also lead to the formation of areas of mucoid degeneration, which play a role in chronic aneurysm and acute dissection associated with aging [35]. The overexpression of osteoblast-related genes and proteins (including RUNX-2, alkaline phosphatase (ALP), collagen I, and BMP2) in senescent VSMCs leads to partial osteoblast transdifferentiation and vascular calcification [36]. Moreover, the increase in stiffness in the aging aorta is related to changes in the mechanical properties of VSMCs. Further, $\beta 1$-integrin and $\alpha$-smooth muscle actin are thought to be the main factors contributing to increased VSMC stiffness during aging [37]. Therefore, both EC and VSMC senescence can lead to vascular aging and related diseases including hypertension, atherosclerosis, aneurysm, and vascular dissection.

\section{3. miRNAs and lncRNAs}

miRNAs are short ( $22 \mathrm{nt})$ single-stranded ribonucleic acid molecules that bind the $3^{\prime}$-untranslated region (UTR) of a target gene, preventing the translation or promoting the degradation of the gene at the posttranscriptional level, thereby negatively regulating expression [38]. miRNAs begin with the transcription of primary RNA and are processed by RNase III DROSHA into 70 nt stem-loop transcripts, known as precursor- (pre-) miRNAs. Pre-miRNAs are then exported to the cytoplasm and processed by RNase III DICER1 into a mature $\sim 22$ nt double-stranded miRNA $[39,40]$. One strand binds Argonaute (AGO) to form an RNA-induced silencing (RISC) complex when the double strands are unraveled [38]. miRNAs play a role in many biological processes including development, cell proliferation and differentiation, 
apoptosis, and immune regulation by negatively regulating the expression of target genes in cells [41]. In addition, miRNAs are also involved in the occurrence and development of many diseases, such as coronary heart disease, myocardial infarction, and heart failure, and can therefore be used as disease markers [42].

lncRNAs are broadly defined as ncRNA molecules longer than $200 \mathrm{nt}$. Most are transcribed by RNA polymerase II, and thus, they have a $5^{\prime}$-methylguanosine cap and a $3^{\prime}$-poly(A) tail structure, but lack the ability to encode proteins [43]. lncRNAs exist in many subcellular structures; however, initial studies have shown that they tend to be located in the nucleus and can activate or inhibit gene expression by introducing chromatin-modifying enzymes at specific genomic sites [44]. IncRNAs can also be used as a bait to separate transcription factors from genomic targets and inhibit gene transcription [45]. A substantial population of lncRNAs also exists in the cytoplasm to regulate mRNA and protein stability and translation, as well as function as miRNA sponges [45]. IncRNAs participate in many biological processes, such as cell proliferation, morphogenesis, pluripotency, development, neuronal processes, and gametogenesis, through transcriptional and posttranscriptional activity [46].

\section{4. miRNAs and lncRNAs in Vascular Aging}

miRNAs and lncRNAs participate in many physiological and pathological processes, including vascular aging. The role of miRNAs and lncRNAs on senescence in ECs and VSMCs affects the process of vascular aging (Figure 1).

4.1. miRNAs and EC Senescence. ECs play an important role in vascular physiology; EC senescence leads to dysfunction and promotes the occurrence of diseases related to vascular aging. A senescent EC phenotype is associated with increased apoptosis, reduced endothelial nitric oxide synthase (eNOS) production, and inflammation. Many miRNAs are involved in the regulation of EC senescent phenotypes (Table 1). For example, senescent human aortic ECs (HAECs) exhibit reduced expression of proliferation-stimulating or apoptosis-suppressing miRNAs such as miR-21, miR-214, and miR-92a; increased eNOS-suppressing molecules including miR-221 and miR-222; reduced miR-126, which represses inflammation; and increased miR-125b, which stimulates inflammation. Further, the development of a senescent arterial EC phenotype is characterized by reduced cell proliferation, enhanced apoptosis, and inflammation; additionally, reduced eNOS is associated with changes in these miRNAs. Therefore, miRNAs could play a critical role in arterial EC senescence [47]. In addition to suppressing eNOS, the increased miR-221/222 cluster inhibits their proangiogenic activation, proliferation, and migration in senescent HAECs [48].

Studies have found that many miRNAs are involved in the RS of ECs. For example, miR-92a is upregulated in the aged vascular endothelium, and oxidative stress or inflammation can be suppressed by inhibiting miR-92a expression and regulating the Nrf2-Keap1-antioxidant response element (ARE) signaling pathway, thus inhibiting endothelial apopto- sis and facilitating cell proliferation; thus, the upregulation of miR-92a promotes cell apoptosis in the aged vascular endothelium [49]. However, miR-92a was downregulated in senescent HAECs, which inhibited cell proliferation [47]. Additionally, miR-21 was inconsistently expressed in different senescent ECs. miR-21 was also found to be upregulated in response to replicative and stress-induced senescence, and its overexpression induced $\mathrm{p} 21^{\mathrm{CIP} 1}$ and $\mathrm{pCDK} 2$ expression by targeting $\mathrm{CDC} 25 \mathrm{~A}$ and nuclear factor $1 \mathrm{~B}$ (NF-IB), thus promoting EC senescence [50]. However, the downregulation of miR-21 promoted apoptosis in senescent HAECs [47].

miR-126 is another controversial molecule in endothelial senescence. It was found that the downregulation of miR-126 in senescent human umbilical vein endothelial cells (HUVECs) reduced tube formation and wound healing closure by inhibiting hypoxia-inducible factor- $1 \alpha$ (HIF- $1 \alpha$ ) expression [51]. However, in another study, miR-126-3p levels showed a significant age-related increase in senescent HUVECs. miR-126-3p overexpression enhances cell survival by targeting SPRED-1 and activating the phosphatidyl inositol 3-kinase (PI3K)/AKT/eNOS signaling pathway, which are involved in promoting cell differentiation and survival [52]. More research is required to determine what role these miRNAs play in endothelial senescence.

In ECs undergoing RS, miR-146a, miR-34a, and miR181a are overexpressed, whereas their target, Bcl-2, an antioxidant and antiapoptotic factor that regulates mitochondrial fission/fusion and autophagy, is downregulated, leading to the accumulation of dysfunctional mitochondria, oxidative stress, chronic low-grade inflammation, and increased apoptosis [53]. Interestingly, another study found that miR-146a was downregulated in senescent HUVECs. Moreover, miR-146 affects EC senescence by targeting NOX4, a main source of reactive oxygen species (ROS). Therefore, the downregulation of miR-146a promotes EC senescence by increasing ROS $[54,55]$. In addition, toll-like receptor (TLR) signaling-associated IL-1 receptor- associated kinase (IRAK1), a key mediator of the TLR/IL-1R signaling pathways that leads to the induction of inflammatory target gene expression, is another target of miR-146a [56]. Thus, the downregulation of miR-146a can also promote the expression of inflammatory genes in ECs by increasing the expression of IRAK1 in senescent HUVECs. It is difficult to explain the inconsistencies associated with the roles of miR$146 \mathrm{a}$ in HUVEC senescence, but it was confirmed that miR-146a is involved in EC senescence.

Further, miR-34a expression was increased in senescent HUVECs, and its overexpression was shown to induce EC senescence and suppresses cell proliferation by inhibiting sirtuin 1 (SIRT1) expression [57]. Moreover, the inhibition of SIRT1, an $\mathrm{NAD}^{+}$-dependent protein deacetylase, induces a premature senescence-like phenotype by increasing the acetylation of p53 and plasminogen activator inhibitor-1 (PAI-1) expression and decreasing both the protein expression and activity of eNOS [58]. P53 can also increase the expression of miR-34a in ECs [59]. This increase can induce senescence and vascular aging via the downregulation of its direct target gene Sirt1, which increases the acetylation of p53 and further 


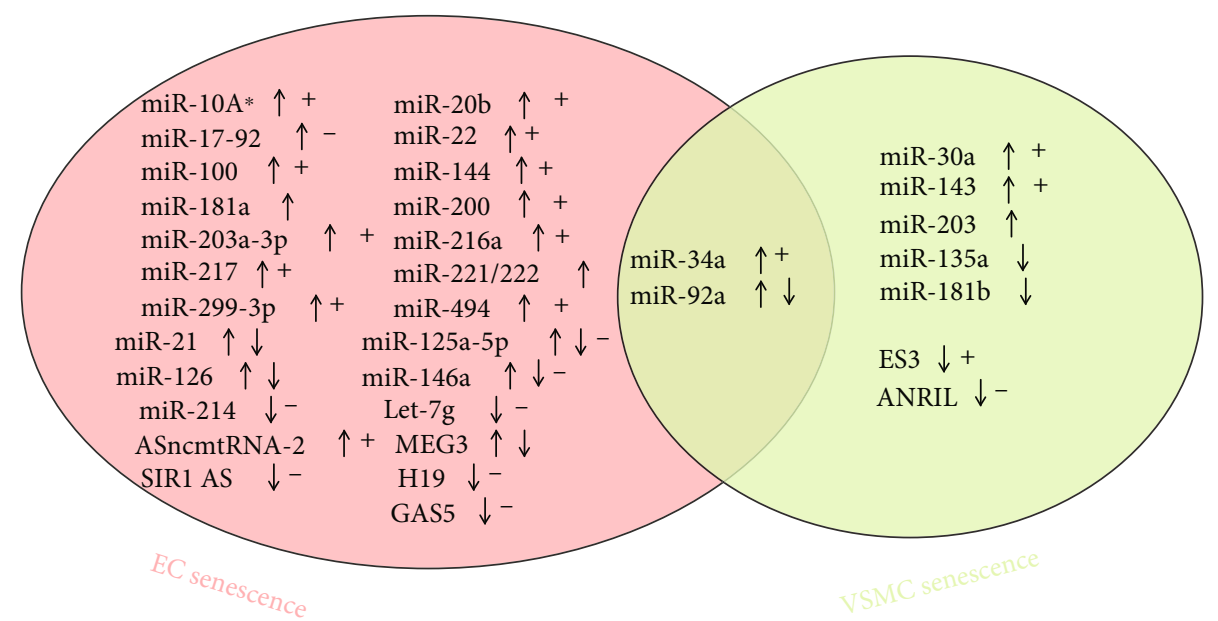

FIGURE 1: miRNAs and lncRNAs in the senescence of endothelial cells (ECs) and vascular smooth muscle cells (VSMCs). ( $\uparrow$ ) and ( $\downarrow$ ) indicate increased and decreased expressions, respectively, during senescence. $(+)$ and $(-)$ indicate the promotion or inhibition of senescence, respectively, by miRNA or lncRNA.

increases the expression of miR-34a. Thus, the miR34a/SIRT1/p53/miR-34a cycle promotes a positive feedback loop of EC senescence. In addition, miR-34a also induces endothelial progenitor cell (EPC) senescence by inhibiting SIRT1 to increase the expression of deacetylated forkhead box O1 (FoxO1), leading to impaired angiogenesis [60]. Moreover, miR-217 induces a premature senescence-like phenotype and leads to impaired angiogenesis via the inhibition of SIRT1 and modulation of FoxO1, as well as eNOS acetylation, in ECs [61].

miR-216a expression is significantly increased in senescent ECs and induces a premature senescence-like phenotype in HUVECs that is associated with impaired proliferation and migration and increased adhesion to monocytes; this is mediated by the inhibition of Smad3 expression and consequently the modulation of NF- $\kappa \mathrm{B}$ inhibitor alpha $(\mathrm{I} \kappa \mathrm{B} \alpha)$ degradation and adhesion molecule activation [62]. miR-216a promotes endothelial senescence and inflammation as an endogenous inhibitor of the $\operatorname{Smad} 3 / \mathrm{I} \kappa \mathrm{B} \alpha$ pathway [62]. In addition, miR-22 was found to be upregulated in senescent EPCs. Accordingly, the overexpression of miR-22 in young EPCs induced cell senescence, decreased proliferation and migration, and impaired angiogenesis by sponging AKT3 (also known as protein kinase B3 (PKB3)) [63]. AKT3, one of the three AKT subtypes, is a serine/threonine kinase that promotes cell survival signals through the PI3K pathway, leading to the inactivation of apoptotic proteins [64]. miR$125 a-5 p$ expression was found to be upregulated in senescent arterial ECs, resulting in impaired angiogenesis through the targeting of RTEF-1 and the downregulation of eNOS and vascular endothelial growth factor (VEGF) [65].

Interestingly, the opposite is true for stress-induced EC senescence. Specifically, the expression of miR-125a-5p is decreased in oxidized low-density lipoprotein- (ox-LDL-) treated human brain microvascular endothelial cells (HBMECs). A further study found that miR-125a-5p overexpression could inhibit HBMEC senescence while promoting $\mathrm{NO}$ generation and reducing ROS production via PI3K/AK-
T/eNOS signaling [66]. These results suggest that miR-125a$5 \mathrm{p}$ plays a regulatory role through different signaling pathways during adaptation to different aging stresses. miR-299-3p is upregulated in senescent HUVECs, and one of its target genes could be insulin-like growth factor-1 (IGF1). Further, the knockdown of hsa-miR-299-3p was found to rescue cells from senescence induced by $\mathrm{H}_{2} \mathrm{O}_{2}$ treatment [67].

miR-10A* and miR-21 are upregulated in aged mice; Hmga2 is a shared molecular target of these miRNAs and a critical regulator of EPC senescence. The overexpression of miR-10A* and miR-2 1 in young EPCs causes EPC senescence, decreases self-renewal potential, increases $\mathrm{p} 16^{\text {Ink4a }} / \mathrm{p} 19^{\text {Arf }}$ expression by inhibiting Hmga2 expression, and eventually results in impaired EPC angiogenesis [68]. Further, miR126, miR-21, and miR-100 levels were increased in senescent HUVECs, which decreased the glycolysis rate and reduced stress tolerance by targeting nuclear factor E2related factor 2 (NRF2), a key antiaging transcription factor regulating oxidative stress responses and angiogenic capacity [69-71]. Furthermore, the upregulation of miR-144 in aged CMVECs also decreased the expression of NRF2, leading to increased age-related oxidative stress and impaired angiogenesis [72].

The miR-17-92 cluster encodes seven mature miRNAs: miR-17-5p, miR-17-3p, miR-18a, miR-19a, miR-20a, miR$19 \mathrm{~b}$, and miR-92a. One study found that miR-17, miR19b, miR-20a, and miR-106a were downregulated in senescent HUVECs and that a decrease in these miRNAs was correlated with increased transcript levels of CDK inhibitor p21/CDKN1A, establishing these miRNAs as novel markers of cellular aging in humans [73]. Another study found that miR-18a expression was decreased in aging ECs and miR$18 \mathrm{a}$ protects ECs from hypoxia/reoxygenation-induced injury by downregulating the Nox2/ROS pathway [74]. In addition, some components of the miR-17-92 cluster (miR18a, miR-17-5p, and miR-20a) may participate in the control of angiogenic phenotypes such as the proliferation, survival, 
TABLE 1: MicroRNAs in vascular aging.

\begin{tabular}{|c|c|c|c|c|c|}
\hline MicroRNA & Cell type & Pathway & $\begin{array}{l}\text { Effect on } \\
\text { senescence }\end{array}$ & Functional consequences & Reference \\
\hline $\operatorname{miR}-221 / 222(\uparrow)$ & HAEC & N/A & N/A & $\begin{array}{l}\text { Reduced eNOS, inhibited proliferation, } \\
\text { migration, and angiogenesis }\end{array}$ & {$[47,48]$} \\
\hline $\operatorname{miR}-92 \mathrm{a}(\downarrow)$ & HAEC & N/A & N/A & Inhibited proliferation & {$[47]$} \\
\hline $\operatorname{miR}-92 \mathrm{a}(\uparrow)$ & HUVEC & Nrf2-KEAP1-ARE & N/A & Promoted apoptosis & {$[49]$} \\
\hline $\operatorname{miR}-21(\downarrow)$ & HAEC & $\mathrm{N} / \mathrm{A}$ & $\mathrm{N} / \mathrm{A}$ & Promoted apoptosis & {$[47]$} \\
\hline $\operatorname{miR}-21(\uparrow)$ & HUVECs & $\begin{array}{l}\text { Targeting CDC25A } \\
\text { and NFIB }\end{array}$ & \pm & Inhibited angiogenesis and proliferation & {$[50]$} \\
\hline $\operatorname{miR}-126(\downarrow)$ & HUVEC & HIF- $1 \alpha$ & $\mathrm{N} / \mathrm{A}$ & $\begin{array}{l}\text { Inhibited migration, proliferation, and } \\
\text { angiogenesis }\end{array}$ & {$[51]$} \\
\hline $\operatorname{miR}-126(\uparrow)$ & HUVEC & SPRED-1 & N/A & Promoted differentiation and survival & {$[52]$} \\
\hline $\operatorname{miR}-181 \mathrm{a}(\uparrow)$ & HUVECs & Targeting Bcl-2 & N/A & $\begin{array}{l}\text { Promoted oxidative stress, chronic low- } \\
\text { grade inflammation, and apoptosis }\end{array}$ & {$[53]$} \\
\hline $\operatorname{miR}-146 \mathrm{a}(\uparrow)$ & HUVECs & Targeting Bcl-2 & N/A & $\begin{array}{l}\text { Promoted oxidative stress, chronic low- } \\
\text { grade inflammation, and apoptosis }\end{array}$ & {$[53]$} \\
\hline $\operatorname{miR}-146 \mathrm{a}(\downarrow)$ & HUVECs & $\begin{array}{l}\text { Targeting NOX4 and } \\
\text { IRAK1 }\end{array}$ & - & $\begin{array}{l}\text { Increased ROS and promoted } \\
\text { inflammation }\end{array}$ & {$[54-56]$} \\
\hline $\operatorname{miR}-34 \mathrm{a}(\uparrow)$ & $\begin{array}{l}\text { HUVECs, } \\
\text { EPCs }\end{array}$ & $\begin{array}{l}\text { Targeting Bcl-2 and } \\
\text { SIRT1 }\end{array}$ & + & Promoted apoptosis and inflammation & {$[53,57,60]$} \\
\hline $\operatorname{miR}-217(\uparrow)$ & $\begin{array}{l}\text { HUVECs, } \\
\text { HAEC }\end{array}$ & Targeting SIRT1 & + & Inhibited angiogenesis & {$[61]$} \\
\hline $\operatorname{miR}-216 \mathrm{a}(\uparrow)$ & HUVECs & $\mathrm{Smad} 3 / \mathrm{I} \kappa \mathrm{B} \alpha$ & + & $\begin{array}{l}\text { Inhibited proliferation and migration, } \\
\text { increased adhesion to monocytes }\end{array}$ & {$[62]$} \\
\hline $\operatorname{miR}-22(\uparrow)$ & EPCs & Targeting AKT3 & + & $\begin{array}{c}\text { Inhibited proliferation, migration, and } \\
\text { angiogenesis }\end{array}$ & {$[63]$} \\
\hline $\operatorname{miR}-125 \mathrm{a}-5 \mathrm{p}(\uparrow)$ & AEC & Targeting RTEF-1 & N/A & Inhibited angiogenesis & {$[65]$} \\
\hline miR-125a-5p ( $\downarrow)$ & HBMEC & PI3K/Akt/eNOS & - & $\begin{array}{l}\text { Promoted apoptosis and inhibited } \\
\text { proliferation, migration, and angiogenesis }\end{array}$ & {$[66]$} \\
\hline miR-299-3p ( $\uparrow)$ & HUVECs & Targeting IGF1 & + & Inhibited proliferation, migration & {$[67]$} \\
\hline $\operatorname{miR}-10 \mathrm{~A} * / \mathrm{miR}-21(\uparrow)$ & EPCs & Targeting Hmga2 & + & Inhibited angiogenesis & {$[68]$} \\
\hline miR-126/miR-21/miR-100 ( $\uparrow)$ & HUVEC & Targeting NRF2 & + & $\begin{array}{c}\text { Decreased the glycolysis rate and stress } \\
\text { tolerance }\end{array}$ & {$[69]$} \\
\hline $\operatorname{miR}-144(\uparrow)$ & CMVEC & Targeting NRF2 & + & $\begin{array}{l}\text { Increased oxidative stress and inhibited } \\
\text { angiogenesis }\end{array}$ & {$[71]$} \\
\hline miR-17-92 ( $\downarrow)$ & HUVEC & p21/CDKN1A & - & $\begin{array}{c}\text { Inhibited proliferation, survival, and } \\
\text { angiogenesis }\end{array}$ & {$[72-75]$} \\
\hline $\operatorname{miR}-214(\downarrow)$ & HMVEC & Targeting ATM & - & Inhibited angiogenesis & {$[76]$} \\
\hline $\operatorname{miR}-494(\uparrow)$ & HUVECs & Targeting MRN & + & Inhibited angiogenesis & {$[77]$} \\
\hline $\operatorname{miR}-21-5 p / 203 a-3 p(\uparrow)$ & HUVECs & Drp1/AMPK-p53/p16 & + & Mitochondrial dysfunction & {$[78,79]$} \\
\hline $\operatorname{miR}-20 \mathrm{~b}(\uparrow)$ & HMVEC & Targeting RBL1 & + & Inhibited proliferation & {$[80]$} \\
\hline $\operatorname{miR}-200 \mathrm{c}(\uparrow)$ & HUVECs & Targeting ZEB1 & + & Inhibited proliferation & {$[81]$} \\
\hline $\operatorname{miR}-200 \mathrm{~b}(\uparrow)$ & $\mathrm{EPC}$ & Targeting c-Jun & + & Promoted apoptosis & {$[82]$} \\
\hline $\operatorname{miR}-200 \mathrm{a}(\uparrow)$ & $\begin{array}{l}\text { Cavernous } \\
\text { ECs }\end{array}$ & SIRT1/eNOS/NO/PKG & + & Attenuated endothelial function & {$[83]$} \\
\hline Let-7g $(\downarrow)$ & HUVECs & SIRT1/TGF- $\beta$ & - & $\begin{array}{l}\text { Increased inflammation, monocyte } \\
\text { adhesion and decreased angiogenesis }\end{array}$ & {$[84,85]$} \\
\hline $\operatorname{miR}-34 \mathrm{a}(\uparrow)$ & HASMCs & Targeting SIRT1 & + & $\begin{array}{l}\text { Promoted inflammation and vascular } \\
\text { calcification, inhibited proliferation }\end{array}$ & {$[86,87]$} \\
\hline $\operatorname{miR}-30 \mathrm{a}(\uparrow)$ & VSMCs & Targeting Beclin 1 & + & Inhibited autophagy & {$[88]$} \\
\hline $\operatorname{miR}-92 \mathrm{a}(\downarrow)$ & VSMCs & TNFR1 & N/A & Promoted aortic stiffness & {$[89]$} \\
\hline $\operatorname{miR}-143(\uparrow)$ & VSMCs & Targeting AKT & + & Inhibited proliferation, migration & {$[90]$} \\
\hline $\operatorname{miR}-181 b(\downarrow)$ & VSMCs & TGF- $\beta$ & $\mathrm{N} / \mathrm{A}$ & Promoted vascular stiffness & {$[91]$} \\
\hline
\end{tabular}


Table 1: Continued.

\begin{tabular}{|c|c|c|c|c|c|}
\hline MicroRNA & Cell type & Pathway & $\begin{array}{c}\text { Effect on } \\
\text { senescence }\end{array}$ & Functional consequences & Reference \\
\hline $\operatorname{miR}-203(\uparrow)$ & $\begin{array}{l}\text { Aortic } \\
\text { SMCs }\end{array}$ & $\begin{array}{c}\text { Targeting Src, } \\
\text { caveolin-1 and paxillin }\end{array}$ & N/A & Promoted vascular stiffness & {$[92]$} \\
\hline $\operatorname{miR}-135 \mathrm{a}(\downarrow)$ & VSMCs & KLF4/STAT3 & N/A & Promoted cell calcification & [93] \\
\hline
\end{tabular}

and organization of ECs [75]. Further, miR-214, which is highly expressed in ECs, is enriched in EC-derived exosomes; senescent cells with reduced miR-214 levels can be rescued by absorbing exosomal miR-214 produced by neighboring cells. Finally, miR-214 represses senescence by suppressing ATM, which prevents cell cycle progression [76].

Many miRNAs also play a regulatory role in SIPS in ECs. For example, radiation-induced miR-494 expression exacerbates DNA damage and drives endothelial senescence, which affects telomerase activity, activates p21, inhibits the pRB pathway, and diminishes angiogenic sprouting by targeting the MRE11a-RAD50-NBN complex [77].

miR-21-5p and miR-203a-3p are upregulated during oxLDL-induced HUVEC senescence. Further studies have demonstrated that miR-21-5p/203a-3p promotes ox-LDLinduced EC senescence through the downregulation of dynamin-related protein 1 (Drp1), resulting in imbalances in mitochondrial dynamics, mitochondrial dysfunction, and activation of the AMP-activated protein kinase (AMPK)p53/p16 pathway $[78,79]$. miR-20b, a paralog of the miR17-92 cluster, is upregulated during tumor necrosis factor$\alpha-($ TNF- $\alpha-)$ induced premature senescence. Further, the knockdown of hsa-miR-20b was found to attenuate premature senescence in TNF- $\alpha$-treated human pulmonary microvascular ECs by increasing target $R B L 1$ mRNA expression, but decreasing the protein expression of $\mathrm{p} 16^{\mathrm{INK} 4 \mathrm{a}}[80]$.

The miRNA-200 gene family consists of five members: miR-200a, miR-200b, miR-200c, miR-141, and miR-429. miR-200c was determined to be upregulated when HUVECs were exposed to $\mathrm{H}_{2} \mathrm{O}_{2}$; it was further shown to inhibit cell proliferation due to senescence. ZEB1 is a target of miR$200 \mathrm{c}$, and its downregulation plays a key role in ROSinduced apoptosis and senescence. Further, pRB and p53 play an active role in the upregulation of miRNA-200c and EC senescence induced by $\mathrm{H}_{2} \mathrm{O}_{2}$ [81]. The expression of miR-200b was shown to be related to an aging-associated increase in EPCs; furthermore, research has found that miR-200b regulates apoptosis and senescence by suppressing c-Jun expression, thus negatively affecting the vascular repair capacity of the cells in atherogenesis [82]. miR-200a, another member of the miRNA-200 family, is increased in the corpus cavernosum of aged rats with erectile dysfunction (ED) compared to that in young rats with ED. In addition, the upregulation of miR-200a is involved in the mechanism underlying age-related ED via SIRT1 inhibition and the attenuation of endothelial function through its ability to influence the eNOS/NO/cGMP-dependent protein kinase (PKG) pathway [83].

Let-7g expression is also decreased in Ang II-induced EC senescence, whereas Let-7g overexpression reverses EC senescence [84]. Another study found that this molecule can improve several endothelial functions, including decreases in senescence, inflammation, and monocyte adhesion, as well as increases in angiogenesis, via transforming growth factor- $\beta$ (TGF- $\beta$ ), and SIRT-1 signaling by regulating three target genes (THBS1, TGFBR1, and SMAD2) involved in TGF- $\beta$ signaling and indirectly increasing SIRT-1 expression to prevent EC senescence [85]. These studies suggest that miRNAs are involved in the regulation of EC senescence and promote senescent phenotypes.

4.2. miRNAs and VSMC Senescence. VSMCs also play an important role in vascular physiology. VSMC senescence leads to cell dysfunction and promotes the occurrence of diseases related to vascular aging. Accordingly, accumulating evidence indicates that miRNAs are involved in the regulation of VSMC senescence. For example, miR-34a is highly expressed in the aortas of old mice. Furthermore, miR-34a overexpression in proliferative human aortic smooth muscle cells causes cell cycle arrest in the G0-G1 phase along with enhanced p21 protein levels by targeting SIRT1 and stimulating the induction of proinflammatory factors including interleukin-1 $\beta$ (IL-1 $\beta$ ), IL-8, IL-6, and bone morphogenic protein 2 (BMP2), as well as the chemokine monocyte chemoattractant protein 1 (MCP1) and the intercellular adhesion molecule 1 (ICAM1) [86]. In addition, miR-34a promotes vascular calcification via VSMC mineralization by inhibiting cell proliferation and inducing senescence [87]. miR-34a plays an important role in the senescence of both ECs and VSMCs and shows potential as a therapeutic target for antivascular aging strategies. Moreover, miR-30a is upregulated in senescent VSMCs, and rapamycin can alleviate aging VSMC cycle arrest and inhibit the senescence of these cells by downregulating $\mathrm{miR}-30 \mathrm{a}$, which results in the upregulation of Beclin1 and the activation of autophagy [88].

Further, miR-92a expression is known to be reduced in the arteries of older adults. This reduction increases the arterial expression of type 1 collagen and tumor necrosis factor receptor 1 (TNFR1), which results in arterial dysfunction characterized by impaired carotid artery endotheliumdependent dilation and reduced NO bioavailability, as well as increased aortic stiffness and PWV [89]. However, miR$92 \mathrm{a}$ is upregulated during vascular EC senescence and is known to promote EC apoptosis [48]. Therefore, the inconsistent expression of miR-92a in senescent ECs and VSMCs might be related to different cell types. Nonetheless, this molecule is involved in the regulation of vascular aging.

miR-143 was found to be significantly upregulated in conjunction with the inhibition of AKT signaling in senescent VSMCs induced by $\mathrm{H}_{2} \mathrm{O}_{2}$. In addition, myocyte 
enhancer 2A (MEF2A) promotes the expression of miR-143 via Krüppel-like factor 2 (KLF2). Therefore, the MEF2A/miR-143/AKT pathway promotes aging in VSMCs [90].

miR-181b, another member of the miR-181 family, is decreased in the aortas of older mice, which increases the expression of targets such as TGF- $\beta$ i (TGF- $\beta$ induced) in the aortic VSMCs, thus promoting an increase in PWV, blood pressure, and vascular stiffness mediated by TGF- $\beta$ signaling [91]. However, miR-181a was found to be overexpressed in senescent ECs. Further, the discordant expression of miR-181a and miR-181b is another interesting concept relating to vascular aging.

Aging is known to increase the expression of miR-203, which leads to a decrease in Src, Cav-1, and paxillin, which impairs agonist-induced focal adhesion signaling in aortic smooth muscle cells and increases VSMC stiffness in aortic tissues [92]. miR-135a was also found to be significantly decreased in aging VSMCs, and its inhibition markedly promoted cell calcification and the expression of calcification genes including ALP and Osteocalcin by targeting KLF4 and the KLF4/STAT3 pathway [93].

In addition to VSMCs, the extracellular matrix (ECM) is an important component in the aortic vascular media, and perturbations in ECM deposition are often associated with aging and aneurysms. miR-29 is significantly upregulated in aging arteries, mediating the downregulation of ECM proteins and sensitizing the aorta to the formation of aneurysms [94].

$(\uparrow)$ and $(\downarrow)$ indicate increased and decreased expressions, respectively, during senescence. $(+)$ and (-) indicate the promotion or inhibition of senescence, respectively, by miRNA. N/A: not available.

4.3. IncRNAs and EC Senescence. In addition to miRNAs, lncRNAs have also been found to play an important regulatory role in vascular aging (Table 2). Using RNA-seq, Abdelmohsen et al. found that several lncRNAs were differentially expressed in senescent human fibroblasts compared to their expression in proliferating cells. Three random senescenceassociated lncRNAs (SAL-RNAs) were found to affect the cell fate, and two of them (SAL-RNA2 and SAL-RNA3) were found to be related to cell survival; in contrast, SAL-RNA1 delays cell senescence, which suggests that lncRNAs play an important role in cell cycle control and senescence [95].

Some lncRNAs also participate in EC and VSMC aging, ultimately leading to a vascular aging phenotype. In a study of the aging mechanisms of EPCs, it was found that the overexpression of nicotinamide phosphoribosyltransferase (NAMPT) could promote cell proliferation and inhibit EPC senescence. Further, miR-223 was found to bind and inhibit the expression of NAMPT, whereas lncRNA GAS5 was suggested to alleviate NAMPT inhibition by sponging miR-223. Moreover, GAS5 knockdown remarkably downregulated cell activity and DNA synthesis in EPCs and promoted EPC senescence. Accordingly, miR-223 inhibition could partially attenuate the effects of GAS5 knockdown on NAMPT and EPC senescence. A further study found that the lncRNA GAS5/miR-223/NAMPT axis serves as a critical regulator of EPC proliferation and senescence via PI3K/AKT signaling
[96]. NAMPT expression is decreased significantly in aging EPCs, whereas NAMPT overexpression can rescue these cells from senescence [96]. A subsequent study found that NAMPT upregulates the expression of SIRT1 AS lncRNA, which relieves miR-22-induced SIRT1 downregulation by competitively sponging miR-22 in EPCs. Therefore, NAMPT inhibits EPC senescence through a SIRT1 AS lncRNA/miR-22/SIRT1 pathway and promotes EPC proliferation and migration [97]. In addition, Visfatin was shown to alleviate ox-LDL-induced EPC senescence by inducing SIRT1 expression in EPCs. Further studies showed that SIRT1 upregulation can inhibit EPC senescence through the PI3K/Akt/ERK pathway [98].

Interestingly, the GAS5/miR-223/NAMPT/SIRT1 AS lncRNA/miR-22/SIRT1 axis and PI3K/Akt/ERK signaling pathway both play a regulatory role in EPC senescence. The expression of H19 is decreased in the endothelium of aging mice, and the loss of this marker results in the upregulation of p16 and p21, which inhibit proliferation and budding and increase EC senescence. Moreover, the deletion of H19 was shown to increase STAT3 phosphorylation and promote the expression of IL- 6 and IL-6R $\alpha$. Accordingly, the inhibition of STAT3 activation alleviates the effect of H19 silencing on the expression of p21 and vascular cell adhesion molecule-1. Thus, H19 depletion results in premature senescence and the dysfunction of ECs and induces inflammation via STAT3 signaling in these cells [99]. In addition, it was found that STAT3 induces p21 expression via the transcriptional activation of FoxP3 and by directly binding the $p 21$ gene promoter region $[100,101]$.

The lncRNA maternally expressed gene 3 (MEG3) in blood vessel specimens of aged individuals and mice was shown to be decreased significantly. The decline in the competitive adsorption of MEG3 leads to increased miR-128 expression and decreased Girdin expression, leading to HUVEC senescence and a reduction in platelet phagocytosis in HUVECs [102]. Interestingly, another study found that Meg3 was significantly increased in senescent HUVECs, and that the silencing of Meg3 prevented the agingmediated inhibition of sprouting activity in HUVECs, which may be involved in Meg3-mediated changes in the epigenetic regulation of gene expression [103]. Further, the mitochondrial lncRNA ASncmtRNA-2 was found to be upregulated in the aorta of aged mice and replicative senescent ECs, but not in SIPS induced by ultraviolet light or $\mathrm{H}_{2} \mathrm{O}_{2}$ or in VSMCs, suggesting that its expression might be related to telomere length and cell type specificity. Further studies revealed that ASncmtRNA-2 might be a noncanonical precursor of hsa-miR-4485 and hsa-miR-1973. ASncmtRNA2 can also promote cell cycle arrest at the G2/M phase and cell senescence by producing hsa-miR-4485 and hsamiR-1973 [104]. hsa-miR-4485 interfered with 16S rRNA processing and decreased mitochondrial protein synthesis, leading to bioenergetic dysfunction and increased caspases-3/7 activity, which is a known hallmark of apoptosis induced by mitochondrial dysfunction [105]. These studies suggest that lncRNAs are involved in regulating EC senescence and senescence-related dysfunction through a variety of pathways. 
TABLE 2: lncRNAs in vascular aging.

\begin{tabular}{|c|c|c|c|c|c|}
\hline $\operatorname{lncRNA}$ & Cell type & Pathway & $\begin{array}{c}\text { Effect on } \\
\text { senescence }\end{array}$ & Functional consequences & Reference \\
\hline GAS5 $(\downarrow)$ & EPCs & $\begin{array}{l}\text { miR-223/NAMPT and } \\
\text { PI3K/AKT }\end{array}$ & - & Inhibited proliferation & {$[96]$} \\
\hline SIRT1 AS $(\downarrow)$ & EPCs & $\begin{array}{l}\text { miR-22/SIRT1 and } \\
\text { PI3K/AKT/ERK }\end{array}$ & - & Inhibited proliferation and migration & {$[97,98]$} \\
\hline H19 ( $\downarrow)$ & HUVECs & STAT3 & - & $\begin{array}{l}\text { Inhibited proliferation and angiogenesis, } \\
\text { promoted inflammation }\end{array}$ & [99] \\
\hline MEG3 $(\downarrow)$ & HUVECs & miR-128/Girdin & - & Inhibited platelet phagocytosis & {$[102]$} \\
\hline MEG3 $(\uparrow)$ & HUVEC & $\mathrm{N} / \mathrm{A}$ & + & Inhibited angiogenesis & [103] \\
\hline ASncmtRNA-2 $(\uparrow)$ & HUVECs & $\begin{array}{l}\mathrm{miR}-4485 \text { and miR-1973, } \\
\text { 16S rRNA }\end{array}$ & + & Promoted apoptosis & {$[104,105]$} \\
\hline ANRIL $(\downarrow)$ & VSMCs & miR-181a/SIRT1 & - & Promoted cell viability & {$[114]$} \\
\hline GAS5 (NA) & VSMCs & $\mathrm{p} 53, \mathrm{P} 300$, and $\beta$-catenin & N/A & $\begin{array}{l}\text { Promoted apoptosis and inhibited } \\
\text { proliferation, neointima formation }\end{array}$ & {$[116,117]$} \\
\hline ES3 $(\uparrow)$ & VSMCs & $\mathrm{miR}-34 \mathrm{c}-5 \mathrm{p} / \mathrm{BMF}$ & + & Promoted calcification & [119] \\
\hline
\end{tabular}

The permanent inhibition of cell proliferation is considered a traditional marker of cell senescence; thus, some lncRNAs that inhibit cell proliferation might also be involved in cell senescence (Table 3 ). For example, lncRNA-ATB is increased in HUVECs treated with TGF- $\beta 1$, which reduces HUVEC viability and proliferation. Furthermore, lncRNAATB overexpression upregulates caspase- 3 in HUVECs and promotes atherosclerosis [106]. Additionally, HIF1A-AS1 was found to be upregulated in HUVECs induced by palmitic acid (PA). Moreover, HIF1A-AS1 silencing can reduce PA-induced apoptosis and promote the proliferation of HUVECs. Clopidogrel can also reduce PA-induced apoptosis and promote the proliferation of HUVECs by inhibiting HIF1A-AS1, thereby playing a cardioprotective role [107]. IGF2AS, a natural antisense RNA of IGF2, was found to be upregulated in diabetic myocardial microvascular endothelial cells (mMVEs), whereas the inhibition of IGF2AS upregulated IGF2 and VEGF, promoting the proliferation and invasion of diabetic mMVEs. Hence, IGF2AS might also be involved in angiopathy in type 2 diabetes mellitus [108].

LINC00305 expression is significantly upregulated in response to hypoxia in HUVECs. LINC00305 overexpression suppresses proliferation and enhances apoptosis in HUVECs by sponging miR-136, whereas LINC00305 downregulation has the opposite effects, suggesting that it can promote apoptosis and inhibit proliferation in these cells in response to hypoxia [109].

lncRNA OIP5-AS1 was also found to be significantly overexpressed in HUVECs administered with ox-LDL. Silencing this molecule inhibited apoptosis and promoted proliferation by inducing G0/G1 cycle arrest. A further study found that OIP5-AS1 reduces GSK-3 $\beta$ expression by recruiting EZH2, a critical element of the polycomb repressive complex 2 (PRC2) that directly binds the $G S K-3 \beta$ promoter region [110]. Moreover, lncRNA PINC was found to overexpressed in HUVECs treated with TNF- $\alpha$. PINC knockout promotes the proliferation and inhibits the apoptosis of HUVECs. Therefore, TNF- $\alpha$ might partially induce the apoptosis of vascular ECs via PINC overexpression [111].
Finally, SNHG7 was found to be decreased in human retinal ECs exposed to high-glucose (HG) stimuli. SNHG7 overexpression suppresses the inhibition of SIRT by directly inhibiting miR-543, thereby reducing HG-induced cell proliferation, migration, angiogenesis, and VEGF expression [112]. Thus, SNHG7 is a potential molecular target to attenuate HG-induced angiogenesis through the miR543/SIRT1/VEGF pathway.

In summary, these lncRNAs inhibit the proliferation of ECs through many mechanisms. The above lncRNAs are only a portion of the many lncRNAs involved in endothelial cell proliferation inhibition, but whether proliferation inhibition is caused by cell cycle arrest and cell senescence requires further study.

$(\uparrow)$ and $(\downarrow)$ indicate increased and decreased expressions, respectively, during senescence. $(+)$ and $(-)$ indicate the promotion and inhibition of senescence, respectively, by lncRNAs. N/A: not available.

4.4. IncRNAs and VSMC Senescence. Many studies have found that lncRNAs are also involved in the regulation of VSMC senescence. For example, antisense noncoding RNA in the INK4 locus (ANRIL), a lncRNA encoded in the chromosome 9p21 region, regulates its neighbor, tumor suppressor $\mathrm{CDKN} 2 \mathrm{~A} / \mathrm{B}$, via epigenetic mechanisms and thereby regulates cell proliferation and senescence [113]. ANRIL and Sirtl were found to be downregulated, whereas miR-181a was upregulated, in aging VSMCs. The overexpression of ANRIL can also promote cell viability and inhibit the senescence of VSMCs by directly regulating the expression of miR-181a and alleviating the inhibitory effect of Sirt1, further inhibiting the aging-induced activation of p53/p21 signaling [114]. Therefore, ANRIL downregulation promotes VSMC senescence through the miR181a/Sirt1/p53/p21 pathway.

Growth inhibition specificity 5 (GAS5) is a well-known tumor suppressor lncRNA [115]. GAS5 expression is downregulated in proliferative VSMCs, and its overexpression induces cell cycle arrest at the G0/G1 phase through the 
TABLE 3: lncRNAs associated with proliferation inhibition of endothelial cells and vascular smooth muscle cells.

\begin{tabular}{|c|c|c|c|c|}
\hline $\operatorname{lncRNA}$ & Cell type & Pathway & Functional consequences & Reference \\
\hline ATB & HUVECs & Caspase-3 & Inhibited proliferation, promoted apoptosis & {$[106]$} \\
\hline HIF1A-AS1 & HUVECs & N/A & Inhibited proliferation and promoted apoptosis & {$[107]$} \\
\hline IGF2AS & mMVEs & IGF2/VEGF & Inhibited proliferation and invasion & [108] \\
\hline LINC00305 & HUVEC & Sponging miR-136 & Inhibited proliferation and promoted apoptosis & [109] \\
\hline OIP5-AS1 & HUVEC & GSK- $3 \beta$ & Inhibited proliferation and promoted apoptosis & [110] \\
\hline PINC & HUVEC & N/A & Inhibited proliferation and promoted apoptosis & [111] \\
\hline SNHG7 & hREC & miR543/SIRT1 & Inhibited proliferation, migration and angiogenesis & [112] \\
\hline GAS5 & HUVECs 、 VSMCs & $\beta$-Catenin & Inhibited proliferation, migration, and phenotypic switching & {$[117]$} \\
\hline HIF1A-AS1 & VSMCs & TGF- $\beta 1$ & Inhibited proliferation and promoted apoptosis & {$[120,121]$} \\
\hline lincRNA-p21 & VSMCs & TGF- $\beta 1$, P53 & Inhibited proliferation promoted apoptosis & {$[122,123]$} \\
\hline MEG8 & VSMCs & $\begin{array}{l}\text { miR-181a- } \\
5 \text { p/PPAR } \alpha\end{array}$ & Inhibited proliferation and migration and induced apoptosis & {$[124]$} \\
\hline CASC11 & VSMCs & IL-9 & Inhibited proliferation and promoted apoptosis & {$[126]$} \\
\hline $\begin{array}{l}\text { MRAK048635 } \\
\text { P1 }\end{array}$ & VSMCs & $\mathrm{N} / \mathrm{A}$ & $\begin{array}{l}\text { Inhibited proliferation, promoted apoptosis and phenotypic } \\
\text { switching }\end{array}$ & {$[127]$} \\
\hline
\end{tabular}

p53 pathway, which is associated with cell senescence, inhibiting VSMC proliferation and promoting apoptosis. Regarding its underlying mechanism of action, GAS5 binds p53 and the p53 activator P300 to enhance the stability and activity of p53, resulting in the increased expression of cell cycle inhibitors and apoptosis activation genes, leading to cell cycle arrest and increased apoptosis in VSMCs. Moreover, the overexpression of GAS5 via adenoviral delivery was found to suppress neointima formation in a rat carotid balloon injury model, which was related to an increase in p53 expression and apoptosis in neointimal VSMCs [116]. GAS5 reduces the restenosis of balloon-dilated vessels and is also significantly downregulated in response to hypertensive stress. GAS5 knockdown increases proliferation, migration, and phenotypic switching in VSMCs. Mechanistically, it interacts with $\beta$-catenin and its dysregulation affects $\beta$ catenin nuclear translocation, ultimately altering $\beta$-catenin signaling [117].

The downregulation of GAS5 promotes VSMC proliferation and vascular remodeling, leading to hypertension. Vascular calcification is a prominent feature of arterial aging [118]. In a study on the calcification/senescence of HAVSMCs induced by HG, it was found that lncRNA-ES3 is markedly increased in HA-VSMCs treated with HG, which alleviates the inhibition of BCL-2-modifying factor (BMF), promoting the calcification/senescence of HA-VSMCs by sponging miR-34c-5p. Further, lncRAN-ES3 acts as a competing endogenous RNA (ceRNA) of miR-34c-5p to regulate the expression of BMF in HA-VSMCs. BMF is a member of the proapoptotic Bcl-2 family, which is mainly associated with cell proliferation and apoptosis [119].

Some lncRNAs that inhibit the proliferation of VSMCs might also be involved in cell senescence. For example, HIF1A-AS1 expression is increased in intracranial aneurysms, and its overexpression increases the expression of TGF- $\beta 1$ and inhibits the proliferation of VSMCs. Therefore, HIF1A-AS1 regulates the proliferation of VSMCs by upregulating TGF- $\beta 1$ and participating in the development of intra- cranial aneurysms [120]. HIF1A-AS1 expression is also increased in thoracic aortic aneurysm (TAA) and is positively regulated by BRG1. HIF1A-AS1 silencing suppresses apoptosis and promotes the proliferation of VSMCs. Thus, BRG1 promotes apoptosis and inhibits the proliferation of VSMCs through the mediator HIF1A-AS1 [121].

lincRNA-p21 in aortic media tissues and blood is significantly upregulated in TAA patients. Further, lincRNA-p21 overexpression inhibits proliferation and promotes apoptosis in VSMCs through the activation of TGF- $\beta 1$ signaling [122], and this marker is dramatically increased in atherosclerotic plaques. lincRNA-p21 represses cell proliferation and induces apoptosis in VSMCs by enhancing p53 transcriptional activity. A further study found that lincRNA-p21 binds directly to MDM2, resulting in the release of p53 from MDM2 and its subsequent binding to p300, which enhances the activity of $\mathrm{p} 53$, thereby inhibiting VSMCs proliferation [123]. MEG8 is downregulated in ox-LDL-treated VSMCs, and its overexpression suppresses cell proliferation and migration and induces apoptosis. Further research has found that MEG8 promotes the expression of peroxisome proliferator-activated receptor $\alpha(\operatorname{PPAR} \alpha)$ by sponging miR-181a-5p. PPAR $\alpha$ is a member of the PPAR family and promotes the degradation of cyclin-dependent kinase inhibitors (CDKIs) after its activation. Hence, MEG8 regulates the proliferation and migration of VSMCs via the MEG8/miR-181a/PPAR $\alpha$ axis [124].

lncRNA CASC11 is an oncogene in several types of cancer [125]. Its overexpression represses the proliferation and promotes the apoptosis of VSMCs. Accordingly, the downregulation of CASC11 in the plasma of atherosclerosis patients was found to promote VSMC proliferation and the expression of IL-9, which contributes to atherosclerosis [126]. Further, IncRNA MRAK048635 P1 exhibits low expression during hypertension and decreases its expression, promotes proliferation and migration, and inhibits apoptosis in VSMCs; this is a potentially important factor for vascular remodeling, as it affects VSMC cell function and phenotypic 
switching in essential hypertension [127]. These lncRNAs are representative of many lncRNAs involved in VSMC proliferation inhibition; however, whether these lncRNAs inhibit VSMC proliferation by promoting cell cycle arrest and senescence requires further study.

\section{Conclusions}

Vascular aging inevitably occurs during the process of aging. The senescence of ECs and VSMCs is the major factor in vascular aging and is regulated by miRNAs and lncRNAs. Therefore, miRNAs and lncRNAs comprise potential therapeutic targets for many associated diseases and conditions. For example, the expression of miR-34 family members (miR-34a, miR-34b, and miR-34c) is elevated in heart disease, and the inhibition of these factors with anti-miR-34a/anti-miR-34 has emerged as a promising therapeutic strategy.

miR-29b-3p is highly expressed in the exosomes of bone marrow mesenchymal stem cells (BM-MSCs) of aged mice, and the uptake of these exosomes by adipocytes, muscle cells, and hepatocytes leads to insulin resistance. However, an aptamer-mediated nanocomplex delivery system that downregulates miR-29b-3p in BM-MSC-derived exosomes was found to significantly ameliorate insulin resistance in aged mice [128]. Moreover, levels of miR-214 are significantly decreased in senescent ECs, whereas miR-214 produced by adjacent cells can play an antiaging role through exosomal incorporation into senescent cells [76]. As a membranebound vesicle secreted by cells, exosomes can transport ncRNAs to the target cells without being degraded by RNAse enzymes. After uptake, ncRNAs are released and play a regulatory role [129]. Therefore, it is possible that a combination of exosomes and ncRNAs could be used for the treatment of vascular aging. However, the expression of some miRNAs or lncRNAs is not consistent in vascular aging, and these interventions may have different results. Therefore, further studies are required for its future applications.

\section{Conflicts of Interest}

The authors declare that they have no conflicts of interest.

\section{Acknowledgments}

This work was supported by funding from 2019 Bethune Plan Research Project of Jilin University, 2019 Health Special Project of Jilin Provincial Finance Department (2019SCZT008), 2018 Health Special Project of Jilin Provincial Finance Department, and Jilin Province New Coronary Stent Technology Innovation Center.

\section{References}

[1] X. L. Tian and Y. Li, "Endothelial cell senescence and agerelated vascular diseases," Journal of Genetics and Genomics, vol. 41, no. 9, pp. 485-495, 2014.

[2] A. J. Donato, R. G. Morgan, A. E. Walker, and L. A. Lesniewski, "Cellular and molecular biology of aging endo- thelial cells," Journal of Molecular and Cellular Cardiology, vol. 89, no. Part B, pp. 122-135, 2015.

[3] D. P. Bartel, "MicroRNAs: Genomics, Biogenesis, Mechanism, and Function," Cell, vol. 116, no. 2, pp. 281-297, 2004.

[4] M. E. Dinger, T. R. Mercer, P. P. Amaral et al., "Long noncoding RNAs: insights into function," Cellular Oncology, vol. 31, no. 2, pp. 97-98, 2009.

[5] J. Bartek, Z. Hodny, and J. Lukas, "Cytokine loops driving senescence," Nature Cell Biology, vol. 10, no. 8, pp. 887-889, 2008.

[6] T. Yokoi, K. Fukuo, O. Yasuda et al., "Apoptosis signalregulating kinase 1 mediates cellular senescence induced by high glucose in endothelial cells," Diabetes, vol. 55, no. 6, pp. 1660-1665, 2006.

[7] J. Pordzik, D. Jakubik, J. Jarosz-Popek et al., "Significance of circulating microRNAs in diabetes mellitus type 2 and platelet reactivity: bioinformatic analysis and review," Cardiovascular Diabetology, vol. 18, no. 1, p. 113, 2019.

[8] I. Fomison-Nurse, E. E. L. Saw, S. Gandhi et al., "Diabetes induces the activation of pro-ageing miR-34a in the heart, but has differential effects on cardiomyocytes and cardiac progenitor cells," Cell Death \& Differentiation, vol. 25, no. 7, pp. 1336-1349, 2018.

[9] L. Hayflick, "The limited in vitro lifetime of human diploid cell strains," Experimental Cell Research, vol. 37, no. 3, pp. 614-636, 1965.

[10] J. Campisi, “The biology of replicative senescence," European Journal of Cancer, vol. 33, no. 5, pp. 703-709, 1997.

[11] G. P. Dimri, X. Lee, G. Basile et al., "A biomarker that identifies senescent human cells in culture and in aging skin in vivo," Proceedings of the National Academy of Sciences of the United States of America, vol. 92, no. 20, pp. 9363-9367, 1995.

[12] T. Kuilman, C. Michaloglou, W. J. Mooi, and D. S. Peeper, "The essence of senescence," Genes \& Development, vol. 24, no. 22, pp. 2463-2479, 2010.

[13] T. Minamino and I. Komuro, "Vascular cell senescence: contribution to atherosclerosis," Circulation Research, vol. 100, no. 1, pp. 15-26, 2007.

[14] L. L. Smith, H. A. Coller, and J. M. Roberts, "Telomerase modulates expression of growth-controlling genes and enhances cell proliferation," Nature Cell Biology, vol. 5, no. 5, pp. 474-479, 2003.

[15] T. Minamino and S. Kourembanas, "Mechanisms of telomerase induction during vascular smooth muscle cell proliferation," Circulation Research, vol. 89, no. 3, pp. 237-243, 2001.

[16] T. Minamino, S. A. Mitsialis, and S. Kourembanas, "Hypoxia extends the life span of vascular smooth muscle cells through telomerase activation," Molecular and Cellular Biology, vol. 21, no. 10, pp. 3336-3342, 2001.

[17] R. Hsiao, H. W. Sharma, S. Ramakrishnan, E. Keith, and R. Narayanan, "Telomerase activity in normal human endothelial cells," Anticancer Research, vol. 17, no. 2a, pp. 827832, 1997.

[18] M. Vasa, K. Breitschopf, A. M. Zeiher, and S. Dimmeler, "Nitric oxide activates telomerase and delays endothelial cell senescence," Circulation Research, vol. 87, no. 7, pp. 540-542, 2000.

[19] J. Campisi and F. d'Adda di Fagagna, "Cellular senescence: when bad things happen to good cells," Nature Reviews Molecular Cell Biology, vol. 8, no. 9, pp. 729-740, 2007. 
[20] F. Prattichizzo, M. Bonafè, A. Ceka et al., "Endothelial cell senescence and inflammaging: microRNAs as biomarkers and innovative therapeutic tools," Current Drug Targets, vol. 17, no. 4, pp. 388-397, 2016.

[21] J. M. van Deursen, "The role of senescent cells in ageing," Nature, vol. 509, no. 7501, pp. 439-446, 2014.

[22] T. Hayashi, H. Matsui-Hirai, A. Miyazaki-Akita et al., "Endothelial cellular senescence is inhibited by nitric oxide: implications in atherosclerosis associated with menopause and diabetes," Proceedings of the National Academy of Sciences of the United States of America, vol. 103, no. 45, pp. 1701817023, 2006.

[23] I. Sato, I. Morita, K. Kaji, M. Ikeda, M. Nagao, and S. Murota, "Reduction of Nitric Oxide Producing Activity Associated with in Vitro Aging in Cultured Human Umbilical Vein Endothelial Cell," Biochemical and Biophysical Research Communications, vol. 195, no. 2, pp. 1070-1076, 1993.

[24] H. Matsushita, E. Chang, A. J. Glassford, J. P. Cooke, C. P. Chiu, and P. S. Tsao, "eNOS activity is reduced in senescent human endothelial cells - preservation by hTERT immortalization," Circulation Research, vol. 89, no. 9, pp. 793-798, 2001.

[25] J. Loscalzo, "Nitric oxide insufficiency, platelet activation, and arterial thrombosis," Circulation Research, vol. 88, no. 8, pp. 756-762, 2001.

[26] M. Hossain, S. M. Qadri, and L. Liu, "Inhibition of nitric oxide synthesis enhances leukocyte rolling and adhesion in human microvasculature," Journal of Inflammation, vol. 9, no. 1, p. 28, 2012.

[27] D. Tsikas, S. Haufe, D. O. Stichtenoth, and J. Jordan, "Nitric oxide and hypertension," Journal of Hypertension, vol. 30, no. 3, pp. 625-626, 2012.

[28] T. Walsh, T. Donnelly, and D. Lyons, "Impaired endothelial nitric oxide bioavailability: a common link between aging, hypertension, and atherogenesis?," Journal of the American Geriatrics Society, vol. 57, no. 1, pp. 140-145, 2009.

[29] Y. Mistry, T. Poolman, B. Williams, and K. E. Herbert, “A role for mitochondrial oxidants in stress-induced premature senescence of human vascular smooth muscle cells," Redox Biology, vol. 1, no. 1, pp. 411-417, 2013.

[30] J. Wang, A. K. Uryga, J. Reinhold et al., "Vascular smooth muscle cell senescence promotes atherosclerosis and features of plaque vulnerability," Circulation, vol. 132, no. 20, pp. 1909-1919, 2015.

[31] R. Ross, "The pathogenesis of atherosclerosis: a perspective for the 1990s," Nature, vol. 362, no. 6423, pp. 801-809, 1993.

[32] C. Iaconetti, S. de Rosa, A. Polimeni et al., "Down-regulation of miR-23b induces phenotypic switching of vascular smooth muscle cellsin vitroandin vivo," Cardiovascular Research, vol. 107, no. 4, pp. 522-533, 2015.

[33] L. Zhang, Z. Xu, Y. Wu, J. Liao, F. Zeng, and L. Shi, “Akt/eNOS and MAPK signaling pathways mediated the phenotypic switching of thoracic aorta vascular smooth muscle cells in aging/hypertensive rats," Physiological Research, vol. 67, no. 4, pp. 543-553, 2018.

[34] P. Lacolley, V. Regnault, A. Nicoletti, Z. Li, and J. B. Michel, "The vascular smooth muscle cell in arterial pathology: a cell that can take on multiple roles," Cardiovascular Research, vol. 95, no. 2, pp. 194-204, 2012.

[35] T. J. Schlatmann and A. E. Becker, "Pathogenesis of dissecting aneurysm of aorta. Comparative histopathologic study of sig- nificance of medial changes," The American Journal of Cardiology, vol. 39, no. 1, pp. 21-26, 1977.

[36] D. G. Burton, H. Matsubara, and K. Ikeda, "Pathophysiology of vascular calcification: pivotal role of cellular senescence in vascular smooth muscle cells," Experimental Gerontology, vol. 45, no. 11, pp. 819-824, 2010.

[37] H. Qiu, Y. Zhu, Z. Sun et al., "Short communication: vascular smooth muscle cell stiffness as a mechanism for increased aortic stiffness with aging," Circulation Research, vol. 107, no. 5, pp. 615-619, 2010.

[38] R. W. Carthew and E. J. Sontheimer, "Origins and mechanisms of miRNAs and siRNAs," Cell, vol. 136, no. 4, pp. 642-655, 2009.

[39] V. N. Kim, "MicroRNA biogenesis: coordinated cropping and dicing," Nature Reviews Molecular Cell Biology, vol. 6, no. 5, pp. 376-385, 2005.

[40] Y. Tomari and P. D. Zamore, "MicroRNA biogenesis: drosha can't cut it without a partner," Current Biology: CB, vol. 15, no. 2, pp. R61-R64, 2005.

[41] S. L. Ameres and P. D. Zamore, "Diversifying microRNA sequence and function," Nature Reviews Molecular Cell Biology, vol. 14, no. 8, pp. 475-488, 2013.

[42] S. De Rosa, F. Eposito, C. Carella et al., "Transcoronary concentration gradients of circulating microRNAs in heart failure," European Journal of Heart Failure, vol. 20, no. 6, pp. 1000-1010, 2018.

[43] R. Spizzo, M. I. Almeida, A. Colombatti, and G. A. Calin, "Long non-coding RNAs and cancer: a new frontier of translational research?," Oncogene, vol. 31, no. 43, pp. 4577-4587, 2012.

[44] A. Fatica and I. Bozzoni, "Long non-coding RNAs: new players in cell differentiation and development," Nature Reviews Genetics, vol. 15, no. 1, pp. 7-21, 2014.

[45] P. J. Batista and H. Y. Chang, "Long noncoding RNAs: cellular address codes in development and disease," Cell, vol. 152, no. 6, pp. 1298-1307, 2013.

[46] M. Guttman, I. Amit, M. Garber et al., "Chromatin signature reveals over a thousand highly conserved large non- coding RNAs in mammals," Nature, vol. 458, no. 7235 , pp. $223-$ 227, 2009.

[47] C. Rippe, M. Blimline, K. A. Magerko et al., "MicroRNA changes in human arterial endothelial cells with senescence: relation to apoptosis, eNOS and inflammation," Experimental Gerontology, vol. 47, no. 1, pp. 45-51, 2012.

[48] D. A. Chistiakov, I. A. Sobenin, A. N. Orekhov, and Y. V. Bobryshev, "Human miR-221/222 in physiological and atherosclerotic vascular remodeling," BioMed Research International, vol. 2015, Article ID 354517, 18 pages, 2015.

[49] H. Liu, H. Y. Wu, W. Y. Wang, Z. L. Zhao, X. Y. Liu, and L. Y. Wang, "Regulation of miR-92a on vascular endothelial aging via mediating Nrf 2-KEAP1-ARE signal pathway," European Review for Medical and Pharmacological Sciences, vol. 21, no. 11, pp. 2734-2742, 2017.

[50] H. Dellago, B. Preschitz-Kammerhofer, L. Terlecki-Zaniewicz et al., "High levels of oncomiR-21 contribute to the senescence-induced growth arrest in normal human cells and its knock-down increases the replicative lifespan," Aging Cell, vol. 12, no. 3, pp. 446-458, 2013.

[51] M. Alique, G. Bodega, C. Giannarelli, J. Carracedo, and R. Ramírez, "MicroRNA-126 regulates Hypoxia-Inducible Factor- $1 \alpha$ which inhibited migration, proliferation, and 
angiogenesis in replicative endothelial senescence," Scientific Reports, vol. 9, no. 1, p. 7381, 2019.

[52] X. Q. Sui, Z. M. Xu, M. B. Xie, and D. A. Pei, "Resveratrol inhibits hydrogen peroxide-induced apoptosis in endothelial cells via the activation of PI3K/Akt by miR-126," Journal of Atherosclerosis and Thrombosis, vol. 21, no. 2, pp. 108-118, 2014.

[53] M. R. Rippo, F. Olivieri, V. Monsurrò, F. Prattichizzo, M. C. Albertini, and A. D. Procopio, "MitomiRs in human inflamm-aging: A hypothesis involving miR-181a, miR-34a and miR-146a," Experimental Gerontology, vol. 56, pp. 154163, 2014.

[54] M. Vasa-Nicotera, H. Chen, P. Tucci et al., "miR-146a is modulated in human endothelial cell with aging," Atherosclerosis, vol. 217, no. 2, pp. 326-330, 2011.

[55] H. Xu, C. Goettsch, N. Xia et al., "Differential roles of PKCalpha and PKCepsilon in controlling the gene expression of Nox4 in human endothelial cells," Free Radical Biology \& Medicine, vol. 44, no. 8, pp. 1656-1667, 2008.

[56] S. Gottipati, N. L. Rao, and W. P. Fung-Leung, "IRAK1: a critical signaling mediator of innate immunity," Cellular Signalling, vol. 20, no. 2, pp. 269-276, 2008.

[57] T. Ito, S. Yagi, and M. Yamakuchi, "MicroRNA-34a regulation of endothelial senescence," Biochemical and Biophysical Research Communications, vol. 398, no. 4, pp. 735-740, 2010.

[58] H. Ota, M. Akishita, M. Eto, K. Iijima, M. Kaneki, and Y. Ouchi, "Sirt1 modulates premature senescence-like phenotype in human endothelial cells," Journal of Molecular and Cellular Cardiology, vol. 43, no. 5, pp. 571-579, 2007.

[59] J. Zhan, S. Qin, L. Lu et al., "miR-34a is a common link in both HIV- and antiretroviral therapy-induced vascular aging," Aging (Albany NY), vol. 8, no. 12, pp. 3298-3310, 2016.

[60] T. Zhao, J. Li, and A. F. Chen, "MicroRNA-34a induces endothelial progenitor cell senescence and impedes its angiogenesis via suppressing silent information regulator 1," American Journal of Physiology-Endocrinology and Metabolism, vol. 299, no. 1, pp. E110-E116, 2010.

[61] R. Menghini, V. Casagrande, M. Cardellini et al., "MicroRNA 217 modulates endothelial cell senescence via silent information regulator 1," Circulation, vol. 120, no. 15, pp. 15241532, 2009.

[62] S. Yang, X. Mi, Y. Chen et al., "MicroRNA-216a induces endothelial senescence and inflammation via $\operatorname{Smad} 3 / \mathrm{I} \kappa \mathrm{B} \alpha$ pathway," Journal of Cellular and Molecular Medicine, vol. 22, no. 5, pp. 2739-2749, 2018.

[63] Y. Zheng and Z. Xu, "MicroRNA-22 induces endothelial progenitor cell senescence by targeting AKT3," Cellular Physiology and Biochemistry: International Journal of Experimental Cellular Physiology, Biochemistry, and Pharmacology, vol. 34, no. 5, pp. 1547-1555, 2014.

[64] M. P. Scheid and J. R. Woodgett, "Unravelling the activation mechanisms of protein kinase B/Akt," FEBS Letters, vol. 546, no. 1, pp. 108-112, 2003.

[65] P. Che, J. Liu, Z. Shan et al., "miR-125a-5p impairs endothelial cell angiogenesis in aging mice via RTEF-1 downregulation," Aging Cell, vol. 13, no. 5, pp. 926-934, 2014.

[66] Q. Pan, X. Liao, H. Liu et al., "MicroRNA-125a-5p alleviates the deleterious effects of ox-LDL on multiple functions of human brain microvessel endothelial cells," American Journal of Physiology. Cell Physiology, vol. 312, no. 2, pp. C119C130, 2017.
[67] H.-L. Jong, M. R. Mustafa, P. M. Vanhoutte, S. AbuBakar, and P.-F. Wong, "MicroRNA 299-3p modulates replicative senescence in endothelial cells," Physiological Genomics, vol. 45, no. 7, pp. 256-267, 2013.

[68] S. Zhu, S. Deng, Q. Ma et al., "MicroRNA-10A* and MicroRNA-21 modulate endothelial progenitor cell senescence via suppressing high-mobility group A2," Circulation Research, vol. 112, no. 1, pp. 152-164, 2013.

[69] S. M. Kuosmanen, V. Sihvola, E. Kansanen, M. U. Kaikkonen, and A. L. Levonen, "MicroRNAs mediate the senescenceassociated decline of NRF2 in endothelial cells," Redox Biology, vol. 18, pp. 77-83, 2018.

[70] Z. Ungvari, L. Bailey-Downs, D. Sosnowska et al., "Vascular oxidative stress in aging: a homeostatic failure due to dysregulation of Nrf2-mediated antioxidant response," American Journal of Physiology. Heart and Circulatory Physiology, vol. 301, no. 2, pp. H363-H372, 2011.

[71] M. N. Valcarcel-Ares, T. Gautam, J. P. Warrington et al., "Disruption of Nrf2 signaling impairs angiogenic capacity of endothelial cells: implications for microvascular aging," The Journals of Gerontology. Series A, Biological Sciences and Medical Sciences, vol. 67, no. 8, pp. 821-829, 2012.

[72] A. Csiszar, T. Gautam, D. Sosnowska et al., "Caloric restriction confers persistent anti-oxidative, pro-angiogenic, and anti-inflammatory effects and promotes anti-aging miRNA expression profile in cerebromicrovascular endothelial cells of aged rats," American Journal of Physiology. Heart and Circulatory Physiology, vol. 307, no. 3, pp. H292-H306, 2014.

[73] M. Hackl, S. Brunner, K. Fortschegger et al., "miR-17, miR19b, miR-20a, and miR-106a are down-regulated in human aging," Aging Cell, vol. 9, no. 2, pp. 291-296, 2010.

[74] Y. Suarez, C. Fernandez-Hernando, J. Yu et al., "Dicer-dependent endothelial microRNAs are necessary for postnatal angiogenesis," Proceedings of the National Academy of Sciences of the United States of America, vol. 105, no. 37, pp. 14082-14087, 2008.

[75] C.Zhang, J.Wang, X. Ma etal., “ACE2-EPC-EXs protect ageing ECs against hypoxia/reoxygenation-induced injury through the miR-18a/Nox2/ROS pathway," Journal of Cellular and Molecular Medicine, vol. 22, no. 3, pp. 1873-1882, 2018.

[76] B. W. M. van Balkom, O. G. de Jong, M. Smits et al., "Endothelial cells require miR-214 to secrete exosomes that suppress senescence and induce angiogenesis in human and mouse endothelial cells," Blood, vol. 121, no. 19, pp. 39974006, 2013.

[77] C. Espinosa-Diez, R. Wilson, N. Chatterjee et al., "MicroRNA regulation of the MRN complex impacts DNA damage, cellular senescence, and angiogenic signaling," Cell Death \& Disease, vol. 9, no. 6, p. 632, 2018.

[78] J. J. Zhang, W. Q. Liu, J. J. Peng, Q. L. Ma, J. Peng, and X. J. Luo, "miR-21-5p/203a-3p promote ox-LDL-induced endothelial cell senescence through down-regulation of mitochondrial fission protein Drp1," Mechanisms of Ageing and Development, vol. 164, pp. 8-19, 2017.

[79] J. J. Zhang, Y. Z. Zhang, J. J. Peng et al., "Atorvastatin exerts inhibitory effect on endothelial senescence in hyperlipidemic rats through a mechanism involving down-regulation of miR-21-5p/203a-3p," Mechanisms of Ageing and Development, vol. 169, pp. 10-18, 2018.

[80] P. F. Wong, J. Jamal, K. L. Tong et al., "Deregulation of hsamiR-20b expression in TNF- $\alpha$-induced premature 
senescence of human pulmonary microvascular endothelial cells," Microvascular Research, vol. 114, pp. 26-33, 2017.

[81] A. Magenta, C. Cencioni, P. Fasanaro et al., "miR-200c is upregulated by oxidative stress and induces endothelial cell apoptosis and senescence via ZEB1 inhibition," Cell Death and Differentiation, vol. 18, no. 10, pp. 1628-1639, 2011.

[82] S. Zhu, S. Deng, C. Jia et al., "Microrna-200b induces endothelial progenitor cell apoptosis and senescence by targeting cjun expression," Circulation, vol. 130, no. 2, p. A20452, 2014.

[83] F. Pan, X. F. Qiu, W. Yu et al., "MicroRNA-200a is upregulated in aged rats with erectile dysfunction and could attenuate endothelial function via SIRT1 inhibition," Asian Journal of Andrology, vol. 18, no. 1, pp. 74-79, 2016.

[84] P. Y. Hsu, W. Y. Lin, R. T. Lin, and S. H. Juo, "MicroRNA let-7g inhibits angiotensin II-induced endothelial senescence via the LOX-1-independent mechanism," International Journal of Molecular Medicine, vol. 41, no. 4, pp. 2243-2251, 2018.

[85] Y. C. Liao, Y. S. Wang, Y. C. Guo, W. L. Lin, M. H. Chang, and S. H. H. Juo, "Let-7g improves multiple endothelial functions through targeting transforming growth factor-Beta and SIRT-1 signaling," Journal of the American College of Cardiology, vol. 63, no. 16, pp. 1685-1694, 2014.

[86] I. Badi, I. Burba, C. Ruggeri et al., "MicroRNA-34a induces vascular smooth muscle cells senescence by SIRT1 downregulation and promotes the expression of age-associated proinflammatory secretory factors," The Journals of Gerontology Series A: Biological Sciences and Medical Sciences, vol. 70, no. 11, pp. 1304-1311, 2015.

[87] I. Badi, L. Mancinelli, A. Polizzotto et al., "miR-34a promotes vascular smooth muscle cell calcification by downregulating SIRT1 (sirtuin 1) and AXL (AXL receptor tyrosine kinase)," Arteriosclerosis, Thrombosis, and Vascular Biology, vol. 38, no. 9, pp. 2079-2090, 2018.

[88] P. Tan, H. Wang, J. Zhan et al., "Rapamycin-induced miR30a downregulation inhibits senescence of VSMCs by targeting beclin 1," International Journal of Molecular Medicine, vol. 43, no. 3, pp. 1311-1320, 2019.

[89] S. Hazra, G. D. Henson, R. G. Morgan et al., "Experimental reduction of miR-92a mimics arterial aging," Experimental Gerontology, vol. 83, pp. 165-170, 2016.

[90] W. Zhao, X. L. Zheng, D. Q. Peng, and S. P. Zhao, "Myocyte enhancer factor $2 \mathrm{~A}$ regulates hydrogen peroxide-induced senescence of vascular smooth muscle cells via microRNA143," Journal of Cellular Physiology, vol. 230, no. 9, pp. 2202-2211, 2015.

[91] D. Hori, B. Dunkerly-Eyring, Y. Nomura et al., "miR-181b regulates vascular stiffness age dependently in part by regulating TGF- $\beta$ signaling," PloS One, vol. 12 , no. 3, p. e0174108, 2017.

[92] C. J. Nicholson, F. Seta, S. Lee, and K. G. Morgan, "MicroRNA-203 mimics age-related aortic smooth muscle dysfunction of cytoskeletal pathways," Journal of Cellular and Molecular Medicine, vol. 21, no. 1, pp. 81-95, 2017.

[93] L. Lin, Y. He, B. L. Xi et al., "MiR-135a suppresses calcification in senescent VSMCs by regulating KLF4/STAT3 pathway," Current Vascular Pharmacology, vol. 14, no. 2, pp. 211-218, 2016.

[94] R. A. Boon, T. Seeger, S. Heydt et al., "MicroRNA-29 in aortic dilation: implications for aneurysm formation," Circulation Research, vol. 109, no. 10, pp. 1115-1119, 2011.
[95] K. Abdelmohsen, A. Panda, M. J. Kang et al., "Senescenceassociated lncRNAs: senescence-associated long noncoding RNAs," Aging Cell, vol. 12, no. 5, pp. 890-900, 2013.

[96] J. Yao, Z. Shi, X. Ma, D. Xu, and G. Ming, "IncRNA GAS5/miR-223/NAMPT axis modulates the cell proliferation and senescence of endothelial progenitor cells through PI3K/AKT signaling," Journal of cellular biochemistry, vol. 120, no. 9, pp. 14518-14530, 2019.

[97] G. F. Ming, K. Wu, K. Hu, Y. Chen, and J. Xiao, "NAMPT regulates senescence, proliferation, and migration of endothelial progenitor cells through the SIRT1 AS lncRNA/miR22/SIRT1 pathway," Biochemical and Biophysical Research Communications, vol. 478, no. 3, pp. 1382-1388, 2016.

[98] G. F. Ming, Y. J. Tang, K. Hu, Y. Chen, W. H. Huang, and J. Xiao, "Visfatin attenuates the ox-LDL-induced senescence of endothelial progenitor cells by upregulating SIRT1 expression through the PI3K/Akt/ERK pathway," International Journal of Molecular Medicine, vol. 38, no. 2, pp. 643-649, 2016.

[99] P. Hofmann, J. Sommer, K. Theodorou et al., "Long non-coding RNA H19 regulates endothelial cell aging via inhibition of STAT3 signalling," Cardiovascular Research, vol. 115, no. 1, pp. 230-242, 2019.

[100] R. Liu, L. Wang, G. Chen et al., "FOXP3 up-regulates p21 expression by site-specific inhibition of histone deacetylase 2/histone deacetylase 4 association to the locus," Cancer Research, vol. 69, no. 6, pp. 2252-2259, 2009.

[101] E. Zorn, E. A. Nelson, M. Mohseni et al., "IL-2 regulates FOXP3 expression in human CD4+CD25+ regulatory T cells through a STAT-dependent mechanism and induces the expansion of these cells in vivo," Blood, vol. 108, no. 5, pp. 1571-1579, 2006.

[102] Y. Lan, Y. J. Li, D. J. Li et al., "Long noncoding RNA MEG3 prevents vascular endothelial cell senescence by impairing miR-128-dependent Girdin downregulation," American Journal of Physiology. Cell Physiology, vol. 316, no. 6, pp. C830-c843, 2019.

[103] R. A. Boon, P. Hofmann, K. M. Michalik et al., "Long noncoding RNA Meg3 controls endothelial cell aging and function: implications for regenerative angiogenesis," Journal of the American College of Cardiology, vol. 68, no. 23, pp. 2589-2591, 2016.

[104] V. Bianchessi, I. Badi, M. Bertolotti et al., "The mitochondrial lncRNA ASncmtRNA-2 is induced in aging and replicative senescence in endothelial cells," Journal of Molecular and Cellular Cardiology, vol. 81, pp. 62-70, 2015.

[105] L. Sripada, K. Singh, A. V. Lipatova et al., "hsa-miR-4485 regulates mitochondrial functions and inhibits the tumorigenicity of breast cancer cells," Journal of Molecular Medicine (Berlin, Germany), vol. 95, no. 6, pp. 641-651, 2017.

[106] H. Yu, S. Ma, L. Sun, J. Gao, and C. Zhao, “TGF- $\beta 1$ upregulates the expression of lncRNA-ATB to promote atherosclerosis," Molecular Medicine Reports, vol. 19, no. 5, pp. 4222-4228, 2019.

[107] J. Wang, L. Chen, H. Li et al., "Clopidogrel reduces apoptosis and promotes proliferation of human vascular endothelial cells induced by palmitic acid via suppression of the long non-coding RNA HIF1A-AS1 in vitro," Molecular and Cellular Biochemistry, vol. 404, no. 1-2, pp. 203-210, 2015.

[108] Z. Zhao, B. Liu, B. Li et al., "Inhibition of long noncoding RNA IGF2AS promotes angiogenesis in type 2 diabetes," Biomedicine \& Pharmacotherapy, vol. 92, pp. 445-450, 2017. 
[109] B. Y. Zhang, Z. Jin, and Z. Zhao, "Long intergenic noncoding RNA 00305 sponges miR-136 to regulate the hypoxia induced apoptosis of vascular endothelial cells," Biomedicine \& Pharmacotherapy, vol. 94, pp. 238-243, 2017.

[110] M. Wang, Y. Liu, C. Li, Y. Zhang, X. Zhou, and C. Lu, "Long noncoding RNA OIP5-AS1 accelerates the ox-LDL mediated vascular endothelial cells apoptosis through targeting GSK$3 \beta$ via recruiting EZH2," American Journal of Translational Research, vol. 11, no. 3, pp. 1827-1834, 2019.

[111] C. Jiang, X. Fang, Y. Jiang et al., "TNF- $\alpha$ induces vascular endothelial cells apoptosis through overexpressing pregnancy induced noncoding RNA in Kawasaki disease model," The International Journal of Biochemistry \& Cell Biology, vol. 72, pp. 118-124, 2016.

[112] N. Ke, L. H. Pi, Q. Liu, and L. Chen, "Long noncoding RNA SNHG7 inhibits high glucose-induced human retinal endothelial cells angiogenesis by regulating miR-543/SIRT1 axis," Biochemical and Biophysical Research Communications, vol. 514, no. 2, pp. 503-509, 2019.

[113] Y. Liu, H. K. Sanoff, H. Cho et al., "INK4/ARF transcript expression is associated with chromosome 9p21 variants linked to atherosclerosis," PloS one, vol. 4, no. 4, p. e5027, 2009.

[114] P. Tan, Y. H. Guo, J. K. Zhan et al., "LncRNA-ANRIL inhibits cell senescence of vascular smooth muscle cells by regulating miR-181a/Sirt1," Biochemistry and Cell Biology, vol. 97, no. 5, pp. 571-580, 2019.

[115] M. Mourtada-Maarabouni, M. R. Pickard, V. L. Hedge, F. Farzaneh, and G. T. Williams, "GAS5, a non-proteincoding RNA, controls apoptosis and is downregulated in breast cancer," Oncogene, vol. 28, no. 2, pp. 195-208, 2009.

[116] R. Tang, X. Mei, Y. C. Wang et al., "LncRNA GAS5 regulates vascular smooth muscle cell cycle arrest and apoptosis via p53 pathway," Biochimica et Biophysica Acta - Molecular Basis of Disease, vol. 1865, no. 9, pp. 2516-2525, 2019.

[117] Y. N. Wang, K. Shan, M. D. Yao et al., "Long noncoding RNA-GAS5: a novel regulator of hypertension-induced vascular remodeling," Hypertension, vol. 68, no. 3, pp. 736748, 2016.

[118] J. K. Zhan, Y. Wang, J. Y. He et al., "Artery calcification, osteoporosis, and plasma adiponectin levels in Chinese elderly," Heart \& Lung, vol. 44, no. 6, pp. 539-543, 2015.

[119] X. Lin, J. K. Zhan, J. Y. Zhong et al., "IncRNA-ES3/miR-34c$5 \mathrm{p} / \mathrm{BMF}$ axis is involved in regulating high-glucose-induced calcification/senescence of VSMCs," Aging, vol. 11, no. 2, pp. 523-535, 2019.

[120] J. Xu, Y. Zhang, L. Chu, W. Chen, Y. du, and J. Gu, "Long non-coding RNA HIF1A-AS1 is upregulated in intracranial aneurysms and participates in the regulation of proliferation of vascular smooth muscle cells by upregulating TGF- $\beta 1$," Experimental and Therapeutic Medicine, vol. 17, no. 3, pp. 1797-1801, 2019.

[121] S. Wang, X. Zhang, Y. Yuan et al., "BRG1 expression is increased in thoracic aortic aneurysms and regulates proliferation and apoptosis of vascular smooth muscle cells through the long non-coding RNA HIF1A-AS1 in vitro," European Journal of Cardio-Thoracic Surgery, vol. 47, no. 3, pp. 439446, 2015.

[122] W. Hu, Z. Wang, Q. Li, J. Wang, L. Li, and G. Jiang, "Upregulation of lincRNA-p21 in thoracic aortic aneurysms is involved in the regulation of proliferation and apoptosis of vascular smooth muscle cells by activating TGF- $\beta 1$ signaling pathway," Journal of Cellular Biochemistry, vol. 120, no. 3, pp. 4113-4120, 2019.

[123] G. Wu, J. Cai, Y. Han et al., "LincRNA-p21 regulates neointima formation, vascular smooth muscle cell proliferation, apoptosis, and atherosclerosis by enhancing p53 activity," Circulation, vol. 130, no. 17, pp. 1452-1465, 2014.

[124] B. Zhang, Y. Dong, and Z. Zhao, "LncRNA MEG8 regulates vascular smooth muscle cell proliferation, migration and apoptosis by targeting PPAR $\alpha$," Biochemical and Biophysical Research Communications, vol. 510, no. 1, pp. 171-176, 2019.

[125] L. Zhang, W. Kang, X. Lu, S. Ma, L. Dong, and B. Zou, "LncRNA CASC11 promoted gastric cancer cell proliferation, migration and invasion in vitro by regulating cell cycle pathway," Cell Cycle, vol. 17, no. 15, pp. 1886-1900, 2018.

[126] K. Tao, Z. Hu, Y. Zhang, D. Jiang, and H. Cheng, "LncRNA CASC11 improves atherosclerosis by downregulating IL-9 and regulating vascular smooth muscle cell apoptosis and proliferation," Bioscience, Biotechnology, and Biochemistry, vol. 83, no. 7, pp. 1284-1288, 2019.

[127] G. Fang, J. Qi, L. Huang, and X. Zhao, "LncRNA MRAK048635 P1 is critical for vascular smooth muscle cell function and phenotypic switching in essential hypertension," Bioscience Reports, vol. 39, no. 3, 2019.

[128] T. Su, Y. Xiao, Y. Xiao et al., "Bone marrow mesenchymal stem cells-derived exosomal MiR-29b-3p regulates agingassociated insulin resistance," ACS Nano, vol. 13, no. 2, pp. 2450-2462, 2019.

[129] J. Zhang, S. Li, L. Li et al., "Exosome and Exosomal MicroRNA: Trafficking, Sorting, and Function," Genomics, Proteomics \& Bioinformatics, vol. 13, no. 1, pp. 17-24, 2015. 


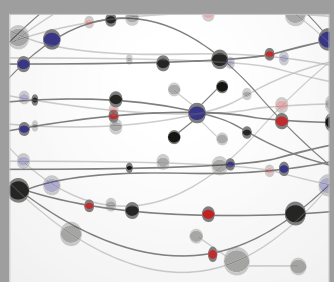

The Scientific World Journal
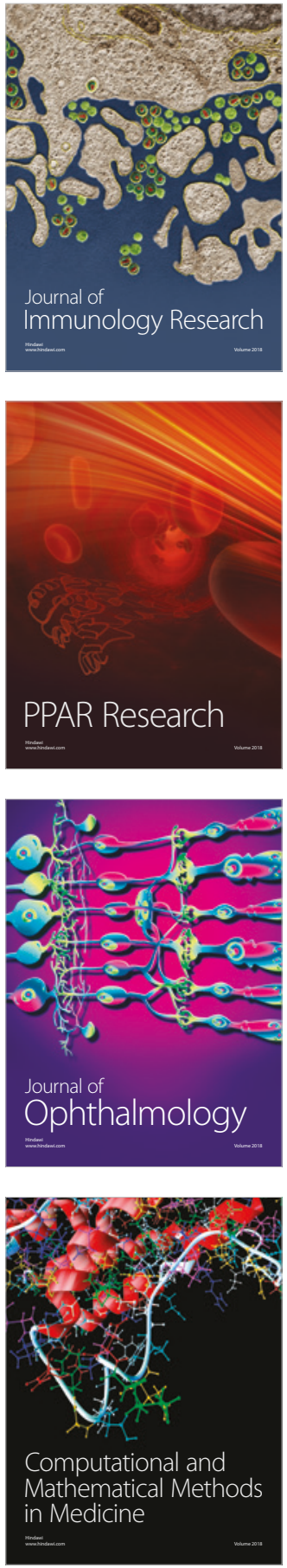

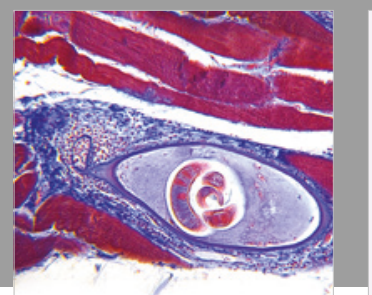

Gastroenterology Research and Practice

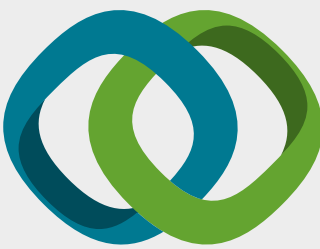

\section{Hindawi}

Submit your manuscripts at

www.hindawi.com
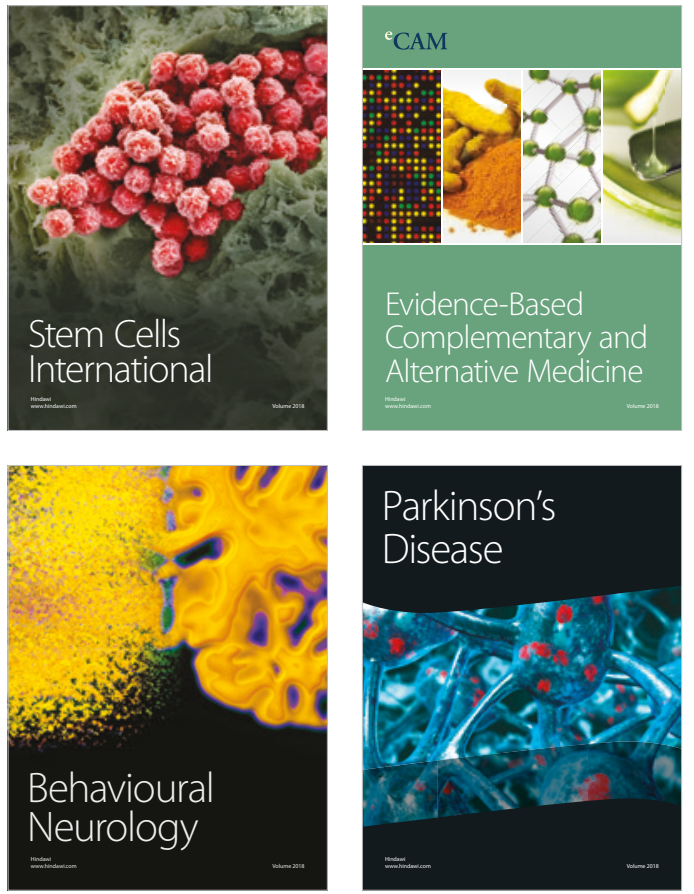

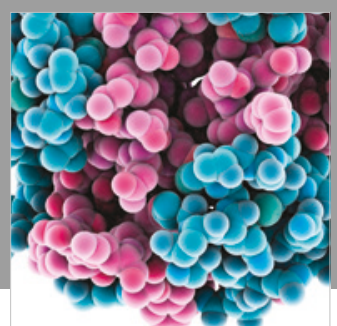

ournal of

Diabetes Research

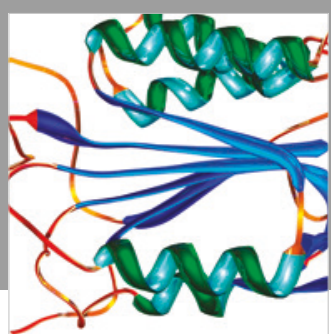

Disease Markers
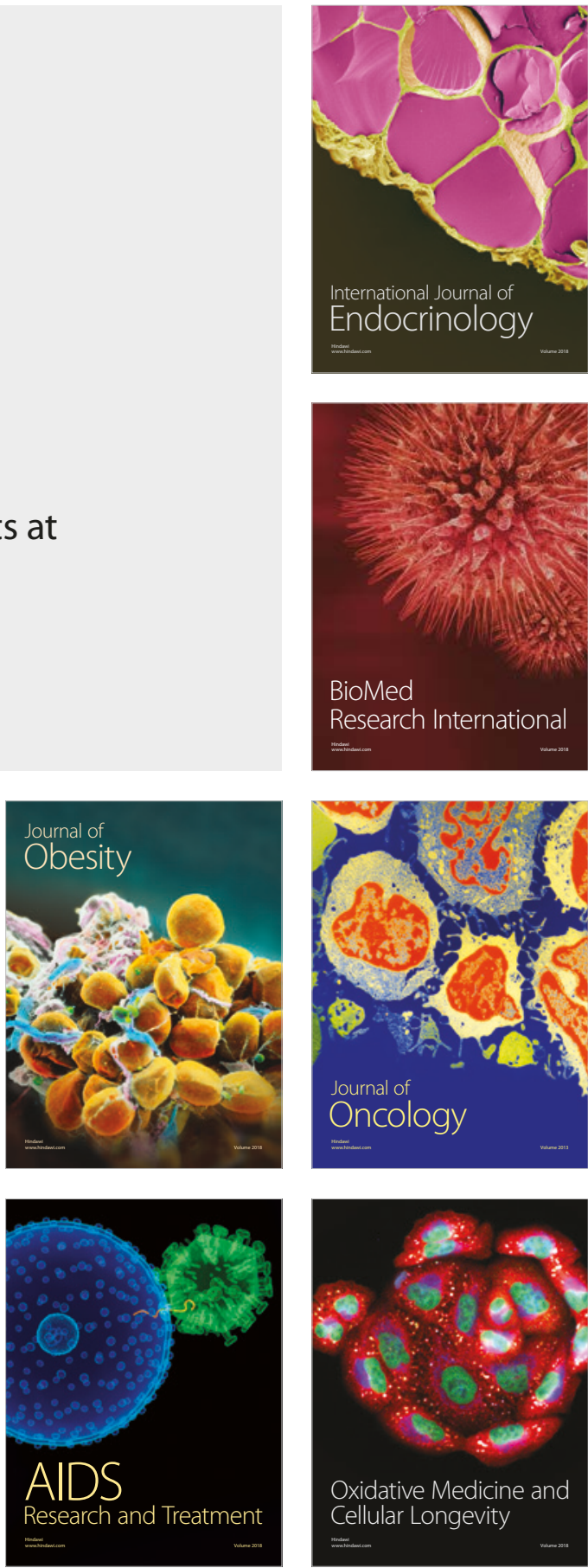